Research Article

\title{
The rs $10455872-G$ allele of the LPA gene is associated with high lipoprotein(a) levels and increased aortic valve calcium in a Mexican adult population
}

\author{
Guillermo Cardoso-Saldaña $^{1}$ iD, José Manuel Fragoso ${ }^{2}$ iD, Shamar Lale-Farjat ${ }^{1}$ (iD, Margarita \\ Torres-Tamayo ${ }^{1}$, Carlos Posadas-Romero ${ }^{1}$ (iD, Gilberto Vargas-Alarcón ${ }^{2}$ (iD and Rosalinda \\ Posadas-Sánchez ${ }^{1}$ (iD) \\ ${ }^{1}$ Department of Endocrinology, Instituto Nacional de Cardiología - Ignacio Chávez, México City, México. \\ ${ }^{2}$ Department of Molecular Biology, Instituto Nacional de Cardiología - Ignacio Chávez, México City, \\ México.
}

\begin{abstract}
Polymorphisms in the LPA gene have been associated with aortic valve calcification (AVC). There are wide differences in the allelic frequencies, $L p(a)$ levels, and the association with AVC among ethnic groups. The aim of this study was to determine the association of the $L P A$ gene polymorphisms with $L p(a)$ levels and risk of developing AVC, in Mexican-Mestizos population. Six LPA polymorphisms (rs10455872, rs7765803, rs6907156, rs1321195, rs12212807 and rs6919346) were genotyped by TaqMan assays in 1,265 individuals without premature coronary artery disease. The presence of AVC was determined by computed tomography. The association of the LPA polymorphisms with AVC, Lp(a), and other cardiovascular risk factors (CVRF) was evaluated using logistic regression analysis. Compared to AA genotype, subjects with $A G+G G$ genotypes had high prevalence of $L p(a) \geq 30 \mathrm{mg} / \mathrm{dL}$ (7.1\% vs. $23.7 \%, p<0.001)$ and AVC (19.0\% vs. $29.4 \%, p=0.007)$. In a model adjusted for several CVRF, the $L P A$ rs10455872-G allele was associated with high $L p(a)$ levels and AVC. Carriers of G allele had a high risk of $L p(a) \geq 30$ $\mathrm{mg} / \mathrm{dL}(\mathrm{OR}=3.86, \mathrm{Cl} 95 \%: 2.2-6.7, p=0.001)$ and $\mathrm{AVC}(\mathrm{OR}=2.54, \mathrm{Cl} 95 \%: 1.56-4.14, p=0.001)$, independently of other CVRF. In this population, carriers of rs $10455872-G$ allele had 3.86 and 2.54 higher risk of $L p(a) \geq 30 \mathrm{mg} / \mathrm{dL}$ or presence of $A V C$, respectively.
\end{abstract}

Keywords: Aortic valve calcification, genetic susceptibility, LPA gene polymorphism.

Received: December 04, 2017; Accepted: November 28, 2018.

\section{Introduction}

Lipoprotein(a) $[\mathrm{Lp}(\mathrm{a})]$ is a low density lipoprotein (LDL) bound to apo(a), a polymorphic glycoprotein of high molecular weight (300 to $800 \mathrm{kDa}$ ) very similar to plasminogen (McLean et al., 1987; Guevara et al., 1992). A high concentration of $\mathrm{Lp}(\mathrm{a})$ is a documented risk factor for coronary artery disease (CAD) (Danesh et al., 2000; Nordestgaard et al., 2010).

Aortic valve calcification (AVC) constitutes one of the first stages of valvular disease that can obstruct blood flow (Kamstrup et al., 2014). This condition has been found in $2 \%$ to $7 \%$ of the population older than 65 years of age (Aronow et al., 1999), and can reach $40 \%$ in individuals with other atherosclerosis risk factors, like smoking, diabetes, hypertension, and dyslipidemia (Taylor et al., 2005).

Send correspondence to Rosalinda Posadas-Sánchez. Department of Endocrinology, Instituto Nacional de Cardiología - Ignacio Chávez, Juan Badiano No. 1, Tlalpan 14080, México City, México. E-mail: rossy_posadas@yahoo.it.
Ethnicity also influences importantly the prevalence of this disease (Nasir et al., 2010; Smith et al., 2014). AVC is an early marker of valvular disease and coronary atherosclerosis as it is associated with a $50 \%$ increase in the risk of myocardial infarction and cardiovascular mortality (Otto et al., 1999).

In the Mexican population without evidence of $\mathrm{CAD}$, prevalence of AVC is of $20 \%$, and is significantly associated with traditional coronary risk factors (Acuña-Valerio et al., 2017)

Several studies have described an independent and significant association of high $\mathrm{Lp}$ (a) concentrations with the presence of AVC (Rajamannan et al., 2011; Kamstrup et al., 2014; Yutzey et al., 2014). However, this association changes widely among ethnic groups (Thanassoulis et al., 2013) probably due to different polymorphisms of some genes, like the $L P A$, the direct influence of $L p(a)$ concentration, and the risk of aortic valve stenosis (Bossé et al., 2008). These observations point out the relevance of considering ethnicity when studying the association between 
Lp(a) and AVC. Previous reports have described Lp(a) concentrations (Cardoso-Saldaña et al., 1997), apo(a) isoforms (Cardoso-Saldaña et al., 2006) and their association with atherosclerosis in Mexican subjects with and without CAD (Baños-González et al., 2010). However, in Mexican-Mestizos, the possible relation of the LPA gene variants to the concentration of $\mathrm{Lp}(\mathrm{a})$ in plasma and the presence of AVC is not known. Hence, the aim of the present study was to evaluate the role of $L P A$ gene polymorphisms, as susceptibility markers for AVC in a population of adult Mexican-Mestizos and whether there is an association with increased concentrations of $\mathrm{Lp}(\mathrm{a})$.

\section{Materials and Methods}

\section{Subjects}

We included 1,265 subjects of the Genetics of the Atherosclerotic Disease (GEA, for its initials in Spanish) Mexican Study, designed at the Instituto Nacional de Cardiología "Ignacio Chavez" in Mexico City to investigate the association of genetic factors with traditional and emerging cardiovascular risk factors in the Mexican adult population (Villarreal -Molina et al., 2012). All GEA participants were Mexican-Mestizos, that is, at least the last three generations have been born in Mexico, and only one person per family was included in the study. Participants were selected from volunteers donating blood at the blood bank, or recruited through invitation among the population attending health community centers in the metropolitan area of Mexico City. We selected individuals from 30 to 75 years of age, without a family and personal history of premature $\mathrm{CAD}$, without acute or chronic inflammatory processes, or a history or clinical evidence of renal (serum creatinine $>$ $1.5 \mathrm{mg} / \mathrm{dL}$ ) or liver (viral hepatitis or drug-induced) diseases. Individuals with cancer or under corticosteroids treatment were not included. The study protocol was approved by the institutional Ethics Committee and performed according to the Helsinki Declaration guidelines. All participants signed an informed consent letter.

Validated questionnaires were applied to the participants to obtain demographic, family and personal history of cardiovascular risk, physical activity, and use of pharmaceuticals information. Weight was determined in kilograms $(\mathrm{kg})$ and height in centimeters $(\mathrm{cm})$ using a calibrated scale and a wall stadiometer. Body mass index (BMI) was calculated with the formula: weight $(\mathrm{kg}) /$ height $\left(\mathrm{m}^{2}\right)$. Waist was measured with a fiberglass metric measure, at the midpoint of the distance between the lower part of the last rib and the iliac crest with a $0.5-\mathrm{cm}$ approximation. Systolic and diastolic arterial pressure was measured three times, in sitting position after at least 5 min rest, and the average of the last two consecutive measurements was considered for the analysis.

\section{Biochemical analysis}

Blood samples were obtained from an antecubital vein after a $10-\mathrm{h}$ fasting period and $20 \mathrm{~min}$ in sitting position. Glucose, total cholesterol, triglycerides, and high density lipoprotein cholesterol (HDL-C) concentrations were determined in the plasma with enzymatic methods (Roche/Hitachi, Germany) in a Hitachi 902 auto-analyzer (Hitachi LTD, Tokyo Japan). Low density lipoprotein cholesterol (LDL-C) was calculated with the Friedewalds formula modified by DeLong et al. (1986), the non-HDL cholesterol was calculated subtracting the HDL-C from the total cholesterol. Reproducibility and accuracy of lipids and lipoproteins determinations were periodically evaluated by the Lipids Standardization Program of the Center for Disease Control and Prevention of the USA (LSP-CDC, Atlanta, GA. USA). Intra- and inter-assay variation coefficients were below 3\%. Lp(a) concentrations was determined through immunonephelometry with the $\mathrm{N}$ Latex Lp(a) reagent (SIEMENS, Health Care Diagnostics Products, GmbH, Marburg, Germany) (Marcovina et al., 2000), in an automatized BN ProSpec $\mathbb{R}$ equipment following the manufacturer's instructions. Intra- and inter-assay variation coefficients were below $6 \%$.

\section{Computed tomography study}

Coronary artery calcification and aortic valve calcification expressed in Hounsfield units (HU) were assessed through 64-detector helical tomography (Somaton Sensation, Siemens, Malvern, PA, USA) with cardiac synchronization by means of a prospective protocol with the following parameters: $120 \mathrm{kV}, 120 \mathrm{~mA}$, and 3-mm slices according to the Agatston method (Mautner et al., 1994). This method correlates significantly with the calcium mass measured directly in the valves (Budoff et al., 2002; Messika-Zeitoun et al., 2004). The aortic wall calcium, found directly connected to the valve's calcium, was included in the AVC score. Images were interpreted by experienced radiologists. The intra-observed variability for AVC was analyzed in 20 random cases, and the correlation coefficient was of 0.99 with $p<0.001$.

\section{Genetic Analysis}

DNA extraction was performed from blood peripheral as described by Lahiri and Nurnberger (1991). The rs10455872, rs7765803, rs6907156, rs1321195, rs12212507 and rs6919346 SNPs of the LPA gene were genotyped using 5exonuclease TaqMan assays on an ABI Prism 7900HT Fast Real-Time PCR System, according to the manufacturers recommendations (Applied Biosystems, Foster City, USA). For each polymorphism, we identified the CAD-risk allele or the minor allele frequency (MAF); subjects carrying the risk allele were compared to homozygotes carrying the wild-type allele.

Because the Mexican-Mestizo population is admixed, in order to assess the possible influence of popula- 
tion stratification, a panel of 265 ancestry informative markers (AIMs) distinguishing mainly Amerindian, European and African ancestry were selected (Silva-Zolezzi et al., 2009) and genotyped on Illumina BeadStation using the GoldenGate assay. Duplicate control samples were genotyped on each chip, which also served as internal controls for quality of clustering and reproducibility. The primary analysis of the genotyping data with the Illumina Genome Studio software v.2011.1 was followed by visual inspection and assessment of data quality and clustering. Genotyping accuracy was also assessed by genotype clustering using the Illumina GeneTrain score, which is a measure of the clustering confidence of individual SNP alleles. Global Caucasian, Amerindian and African ancestry were determined in each individual using the ADMIXTURE software.

\section{Statistical analysis}

Data are expressed as mean and standard deviation, or median and interquartile range for continuous variables, and as frequencies and percentages for categorical variables. Comparisons for continuous variables were performed with Student's $t$ or Mann-Whitney U tests, according to variable distribution, and by chi-square tests for categorical variables. CAC and AVC were analyzed as categorical variables $(\mathrm{CAC}>0$; $\mathrm{AVC}>0 \mathrm{HU})$. Allelic and genotypic frequencies of the polymorphisms of the analyzed molecules were obtained through direct counting, and the Hardy-Weinberg equilibrium was assessed by chi-square analysis. Multivariate logistic regression analysis was used to investigate the independent association between each $L P A$ polymorphisms with the presence of $\mathrm{Lp}(\mathrm{a}) \geq 30$ $\mathrm{mg} / \mathrm{dL}$, the presence of CAC, or AVC $>0 \mathrm{HU}$. Multiple lo- gistic regression models were constructed including one variable at the time, and the final model included variables with biological relevance or with statistical significance. A $p$-value $<0.05$ was considered significant. Analyses were made with the statistics software SPSS V 16.0.

\section{Results}

Of the 1,265 studied subjects, with a mean age of 53.3 \pm 9.4 years, $53 \%$ were women and $47 \%$ men. Prevalence of $\mathrm{Lp}(\mathrm{a})$ of $\geq 30 \mathrm{mg} / \mathrm{dL}, \mathrm{CAC}$ and $\mathrm{AVC}>0 \mathrm{HU}$ were $9.2 \%$, $26.6 \%$, and $20.0 \%$, respectively. In addition, $11.1 \%$ of the study population presented hypertension, $13.7 \%$ had diabetes mellitus, and $21.9 \%$ were active smokers (Table 1). Global ancestry was $54.0 \%, 35.8 \%$, and $10 \%$ of Native American, Caucasian and African ancestry, respectively. The polymorphisms were in Hardy-Weinberg equilibrium (HWE, $p>0.05$ ). The MAF for $\operatorname{rs} 10455872 A>G$, rs7765803 $C>G, \quad \operatorname{rs} 6907156 T>C, \quad \operatorname{rs} 1321195 G>A$, rs $12212507 A>G$ and rs6919346 $C>T$ polymorphisms were $0.087,0.067,0.012,0.128,0.06$ and 0.008 , respectively. Three of the six studied polymorphisms, rs 10455872- $G$ $(p=0.013), \quad \operatorname{rs} 6907156-T \quad(p=0.021)$, and $\operatorname{rs} 7765803-G$ ( $p=0.001$ ) were associated with high $\mathrm{Lp}(\mathrm{a})$ concentrations. Only the rs 10455872- $G$ polymorphism was associated with AVC $>0 \mathrm{HU}(p=0.013)$. No other significant association was observed between the studied LPA polymorphisms with clinical or biochemical variables (data not shown). The population was divided into two groups according to the rs10455872 LPA gene variant: one included the wild-type genotype $(A A)$ carriers and the other the carriers of the $G A$ and $G G$ genotypes.

Table 1 - Characteristics of the Mexican-Mestizo population according to LPA rs10455872 genotype.

\begin{tabular}{|c|c|c|c|c|}
\hline & \multicolumn{4}{|c|}{ Genotypes for $L P A$ rs 10455872} \\
\hline & Total $n=1265$ & $A A \mathrm{n}=1146$ & $A G+G G \mathrm{n}=119$ & $p$ \\
\hline Age (years) & $53.3 \pm 9.4$ & $53.8 \pm 9.1$ & $51.2 \pm 10.6$ & 0.011 \\
\hline Waist $(\mathrm{cm})$ & 94.811 .5 .0 & $94.9 \pm 11.5$ & $94.4 \pm 11.5$ & ns \\
\hline BMI $\left(\mathrm{kg} / \mathrm{m}^{2}\right)$ & $28.5 \pm 4.4$ & $28.5 \pm 4.4$ & $28.6 \pm 4.7$ & ns \\
\hline Systolic blood pressure $(\mathrm{mmHg})$ & $117.3 \pm 17.5$ & $117.9 \pm 18.0$ & $116.8 \pm 17.7$ & ns \\
\hline Diastolic blood pressure (mmHg) & $72.2 \pm 9.4$ & $72.4 \pm 9.6$ & $72.0 \pm 10.0$ & ns \\
\hline Total cholesterol (mg/dL) & $193.1 \pm 37.3$ & $193.1 \pm 37.3$ & $193.3 \pm 33.4$ & ns \\
\hline HDL-C (mg/dL) & $46.0 \pm 13.4$ & $46.3 \pm 13.4$ & $47.3 \pm 14.7$ & ns \\
\hline Triglycerides $(\mathrm{mg} / \mathrm{dL})$ & $147.5(112-201.0)$ & $148.0(112.9-201.0)$ & 138.6(97.0-202.0) & ns* \\
\hline LDL-C (mg/dL) & $118.1 \pm 31.8$ & $118.1 \pm 31.9$ & $118.9 \pm 30.4$ & ns \\
\hline Glucose (mg/dL) & $91.0(84.0-99.0)$ & $91.0(84.3-99.0)$ & $88.0(82.0-97.0)$ & $0.012 *$ \\
\hline $\mathrm{Lp}(\mathrm{a})(\mathrm{mg} / \mathrm{dL})$ & $4.7(2.3-11.7)$ & $4.4(2.3-10.0)$ & $15.4(3.9-29.3)$ & $<0.001 *$ \\
\hline Hypertension (\%) & 11.1 & 11.1 & 10.9 & ns \\
\hline Diabetes mellitus (\%) & 13.7 & 14.1 & 9.2 & ns \\
\hline Smoking $(\%)$ & 21.9 & 21.7 & 23.5 & ns \\
\hline
\end{tabular}

Data is expressed as mean $\pm \mathrm{SD}$ or * median (interquartile range), BMI: Body mass index, LDL-C and HDL-C: low and high density lipoproteins cholesterol, Lp(a): lipoprotein(a): p-values were calculated with ANOVA, * Kruskal-Wallis, and Chi-square test. 
Subjects carrying the $G$ allele ( $A G+G G$ genotypes) were of lower age $(p=0.011)$. Anthropometric, physiological characteristics, as well as lipids, high and low-density lipoprotein concentrations were similar in both groups and not significantly different (Table 1). Compared with wild-type allele, $G$ allele carriers showed a significantly higher Lp(a) plasma levels [15.4 (3.9-29.3 mg/dL vs. 4.4 (2.3-10.0 mg/dL), $p<0.001$, Table 1], higher prevalence of $\mathrm{Lp}(\mathrm{a}) \geq 30 \mathrm{mg} / \mathrm{dL}(23.5 \%$ vs. $7.1 \%, p<0.001)$, and higher prevalence of AVC (29.4\% vs. $19.0 \%, p=0.007$, Figure 1 ). No significant differences were found in the prevalence of $\mathrm{CAC}>0$, or traditional risk factors, such as hypertension, diabetes mellitus, and smoking (Table 1, Figure 1).

The independence of the association between the rs 10455872- $G$ allele with the risk of presenting $L p(a) \geq 30$ $\mathrm{mg} / \mathrm{dL}, \mathrm{CAC}>0$, or AVC $>0 \mathrm{HU}$ was investigated using multivariate logistic regression analysis models. Figure 2 shows the three statistical models used for each variable. The carriers of the $G$ allele had a higher risk of presenting $\mathrm{Lp}(\mathrm{a}) \geq 30 \mathrm{mg} / \mathrm{dL}:$ OR $=4.01(95 \% \mathrm{CI}=2.3-6.9$, $p<0.001)$, unadjusted model; OR $=3.73(95 \% \mathrm{CI}=2.1$ $6.4, p<0.001)$ in a model adjusted for gender and age; and $\mathrm{OR}=3.86(95 \% \mathrm{CI}=2.2-6.7, p=0.001)$ in a model adjusted for several coronary risk factors. The rs $10455872-G$ allele was also associated with the risk of presenting AVC: unadjusted model, $\mathrm{OR}=1.77(95 \% \mathrm{CI}=1.16-2.70$, $p<0.008)$; gender and age adjusted model, $\mathrm{OR}=2.45(95 \%$ $\mathrm{CI}=1.54-3.91, p<0.001)$; and $\mathrm{OR}=2.54(95 \% \mathrm{CI}=1.56$ $4.14, p=0.001$ ) after adjusting for coronary risk factors. The rs 10455872- $G$ allele was not associated with $\mathrm{CAC}>0 \mathrm{HU}$ (Figure 2).

\section{Discussion}

The most relevant result of this study was that, in Mexican-Mestizos without familiar and personal history of premature CAD, the $L P A$ rs $10455872-G$ allele was associated up to 3.86-times with values of $L p(a) \geq 30 \mathrm{mg} / \mathrm{dL}$ and 2.54-times with the presence of AVC, independently of traditional CAD risk factors. Our data also demonstrate that

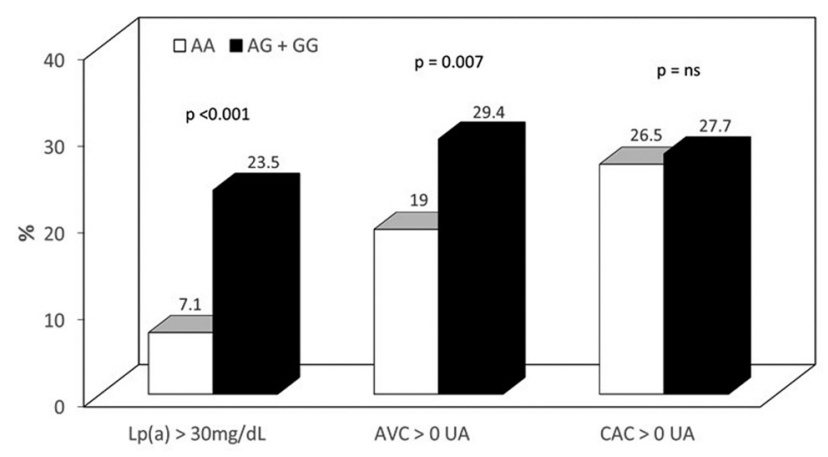

Figure 1 - Prevalence of high Lp(a) levels and presence of aortic valve calcification (AVC) or coronary aortic calcification (CAC) with calcium score $>0$ Hounsfield units (HU) in Mexican-Mestizo rs 10455872- $G$ allele carriers.

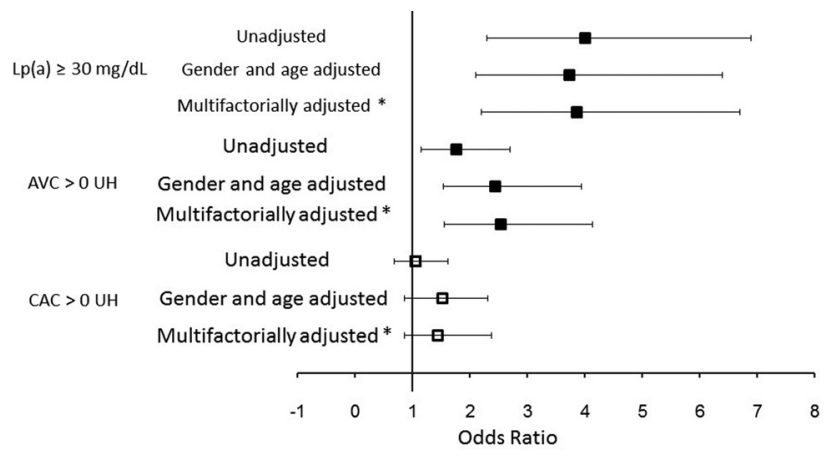

Figure 2 - Multivariate regression analysis demonstrating the independent association between the $L P A$ rs $10455872-G$ allele and $L p(a) \geq 30 \mathrm{mg} / \mathrm{dL}$, $\mathrm{AVC}>0 \mathrm{AU}$ and $\mathrm{CAC}>0 \mathrm{HU}$ in a Mexican-Mestizo population. * adjusted for gender, age, BMI, triglycerides, LDL-C, diabetes mellitus, hypertension, and smoking.

subjects without clinical evidence of aortic valve disease, but carrying this variant of the $L P A$ gene course with AVC, particularly those with high Lp(a) values (Bossé et al., 2008; Thanassoulis et al., 2013; Kamstrup et al., 2014). It is interesting to note that two polymorphisms, rs6907156- $T$ and $\operatorname{rs} 7765803-G$, that were associated with elevated $\mathrm{Lp}(\mathrm{a})$ plasma concentrations in Mexican-Mestizos, did not have effect on CAC or AVC. However, a future development of some inflammatory or chronic diseases (obesity, diabetes mellitus, or dyslipidemia) could impact on the association of $\mathrm{Lp}(\mathrm{a})$ with calcification process.

The concentration of $\mathrm{Lp}(\mathrm{a})$ in humans is genetically determined, and $20 \%$ to $90 \%$ of the variation in $\mathrm{Lp}$ (a) concentration can be explained by $L P A$ gene polymorphisms (Dumitrescu et al., 2011; Kamstrup et al., 2014). The rs 10444872- $G$ allele of the $L P$ A gene has been studied in a general population of different ethnic groups. In Denmark its prevalence is $14 \%$ (Glader et al., 2003), $7 \%$ in European Caucasians (Stewart et al., 1997; Thanassoulis et al., 2013), it is below $1.0 \%$ in South Asia and in China (Lanktree et al., 2010), and 2.0\% in Afro-Americans and Latinos in the USA. However, for the same ethnic groups, the International Genome Sample Resource (IGSR) project, through 1000 GENOMES, reports frequencies below those described in the literature. These results point out the large differences in the prevalence of the rs 10444872- $G$ allele of the $L P A$ gene among ethnic groups and the inconsistency of results obtained for a same group in different studies.

Information on the rs10444872- $G$ allele of the $L P A$ gene in the Mexican population was obtained from samples of Mexican-Americans that migrated to the USA from diverse regions of Mexico, mainly from rural zones were the proportion of an indigenous population is greater, which could explain the inconsistency of the results reported for Mexican-Americans that live in different areas of the USA (Haffner et al., 1992; Kamboh et al., 1997). The frequency of the $L P A$ rs $10455872-G$ allele found in the present study in Mexican-Mestizos was $9.4 \%$, that is, 4.5 -times higher than that informed in Latino or Afro-American populations 
in the USA, 9-times higher than in Asiatic groups; but lower than in Europeans or US Caucasians.

Some studies (Dumitrescu et al., 2011; Kamstrup et al., 2014; Santos et al., 2014; Vongpromek et al., 2015), have shown that patients with AVC present significantly elevated Lp(a) concentrations. However, in a recent comparison on the association of $\mathrm{Lp}(\mathrm{a})$ with AVC in four ethnic groups, this association was found significant in Caucasian and Afro-American subjects, but not in Hispanics or Chinese (Cao et al., 2016). In contrast, the present results for the Mexican-Mestizo population reveal that there is a significant association of $\mathrm{Lp}(\mathrm{a})$ concentration with AVC, independent of other risk factors. The inconsistency of results could be explained by a selection bias, because the Mexican-Mestizo population studied was predominately urban.

The $L P A$ gene polymorphisms have been associated with peripheral and coronary atherosclerosis (Mehrabi et al., 2000), and recently, a large scale genetic meta-analysis showed the association of the $\operatorname{rs} 10455872-G$ allele with AVC (Thanassoulis et al., 2013). Similar results have been obtained in a general population, as well as in patients with CAD of different ethnic groups (Kamstrup et al., 2014). All these results have been replicated in prospective studies performed in an open population (Dumitrescu et al., 2011). Our results demonstrate that the rs $10455872-G$ allele of the $L P A$ gene is associated with the presence of AVC in a Mexican-Mestizo population. Few studies have approached simultaneously the association of $L P A$ gene polymorphisms with $\mathrm{Lp}(\mathrm{a})$ concentrations and AVC in a general population. Recently, in a prospective study nested in the (EPIC)Norfolk Study, patients with high Lp(a) and carriers of the rs 10455872- $G$ allele of gene $L P A$ were found to have a higher risk of aortic valve stenosis, suggesting the possibility of a causal association (Arsenault et al., 2014).

The mechanisms by which the aortic valve becomes mineralized are still unknown. It has been described that high concentrations of $\mathrm{Lp}(\mathrm{a})$ contain oxidized phospholipids, which, when hydrolyzed by phospholipase A2 associated with lipoproteins, generate lysophosphatidylcholine that has pro-inflammatory and osteogenic properties. Evidence in favor of this hypothesis is that both, oxidized phospholipids and lysophosphatidylcholine, have been found elevated in calcified aortic valves (Taleb et al., 2011; Mahmut et al., 2014). Another possible mechanism of aortic mineralization is related to the autotaxin enzyme, secreted by interstitial cells of the valve, which, by binding to $\mathrm{Lp}(\mathrm{a})$, uses as substrate the lysophosphatidylcholine present in the lipoprotein to generate phosphatidic acid, promoting thereby calcium hydroxyapatite deposition in the aortic valve (Bouchareb et al., 2015). More recent research has revealed that lipid infiltration, inflammation, and osteogenesis are frequent pathogenic mechanisms involved in the valvular calcification process. In fact, oxidized LDL and metalloproteinases have been found associated with calcified stenotic valves (Edep et al., 2000; Coté et al.,
2013). As a whole, these studies support the concept that aortic valve disease develops through a process similar to that of coronary atherosclerosis (Miller et al., 2011; Bouchareb et al., 2015).

The present study has the strength of including a large sample of a Mexican-Mestizo population without familial or personal antecedents of CAD or AVC that could bias the results of the analysis of the gene $L P A$ polymorphisms, the prevalence of high $\mathrm{Lp}(\mathrm{a})$, or the presence of coronary or aortic valve calcification. To avoid inaccuracy in determining $\mathrm{Lp}(\mathrm{a})$ concentrations due to differences in apo(a) molecular mass, Lp(a) was determined through immunonephelometry with polyclonal antibodies that allow identifying both small and large isoforms of apo(a) (Marcovina et al., 2000). It is important to emphasize that $G$ allele carriers were of lower age, showing lower fasting glucose levels and lower prevalence of systemic hypertension and diabetes mellitus, which may support the probable causal relation between $\mathrm{Lp}(\mathrm{a})$ and valvular calcium deposition.

This study also has some limitations. First, by being cross-sectional, it does not allow establishing a causality relation, so it only allows making inferences. Second, as the sample was obtained from volunteers, participants may not represent the general population. However, it would be expected that the risk relation would be similar to that of a randomized sample, because of the improbability that the participants in the study could have a previous knowledge on the calcification of their coronary artery, aortic valve, or $L P A$ genotype. In addition, the prevalence of traditional risk factors observed in our study is similar to that reported in the ENSANUT survey of national representation (Hernández-Avila M et al., 1998). Third, in this study, we did not perform hemodynamic measurements, and hence, we are unable to estimate the possible presence of aortic stenosis, although this alteration is quite improbable considering the low Hounsfield scores found in the studied population.

\section{Conclusions}

Our study performed on an asymptomatic MexicanMestizos population demonstrates a significant and independent association of the rs 10455872- $G$ allele of the $L P A$ gene with high $\mathrm{Lp}(\mathrm{a})$ levels and with the presence of AVC. In this ethnic group, the $\mathrm{Lp}(\mathrm{a})$ prevalence higher than 30 $\mathrm{mg} / \mathrm{dL}$, coronary artery calcification, and the presence of aortic valvular calcium were of $9.2 \%, 26.6 \%$, and $20 \%$, respectively. Our data point out the need to perform longitudinal studies that would allow characterizing the role of LPA gene polymorphisms as genetic markers for high $\mathrm{Lp}$ (a) levels and elevated risk for aortic valvular calcification in Mexicans.

\section{Acknowledgments}

This work was supported in part by grants from the Consejo Nacional de Ciencia y Tecnología (project number 
150537). The authors are grateful to the study participants, as well as the clinical staff of the Genetics of the Atherosclerotic Disease (GEA) study.

\section{Conflict of interests} terest.

The authors declare that there are no conflicts of in-

\section{Author contributions}

GCS, RPS, CPR, GVA: Conceived and designed the study; JMF, SLF, GCS: Conducted the experiments; GCS, RPS, MTT: Analyzed the data; GCS, CRP, GVA: Wrote the manuscript. All Authors read and approved the final version of the manuscript.

\section{References}

Acuña-Valerio J, Rodas-Díaz MA, Macias-Garrido E, PosadasSánchez R, Juárez-Rojas JG, Medina-Urrutia AX, Cardoso-Saldaña GC, Joge-Galarza E, Torres-Tamayo M, Vargas-Alarcón G et al. (2017) Aortic valve calcification prevalence and association with coronary risk factors and atherosclerosis in mexican population. Arch Cardiol Mex 87:108-115.

Aronow WS, Ahn C, Shirani J and Kronzon I (1999) Comparison of frequency of new coronary events in older subjects with and without valvular aortic sclerosis. Am J Cardiol 83:599-600.

Arsenault BJ, Boekholdt SM, Dubé MP, Rhéaume É, Wareham NJ, Khaw KT, Sandhu MS and Tardif JC (2014) Lipoprotein(a) levels, genotype, and incident aortic valve stenosis a prospective mendelian randomization study and replication in a case-control cohort. Circ Cardiovasc Genet 7:304-310.

Baños-González MA, Peña-Duque MA, Anglés-Cano E, Martinez-Rios MA, Bahena A, Valente-Acosta B, Cardoso-Saldaña G, Angulo-Ortíz J and de la Peña-Díaz A (2010) Apo(a) phenotyping and long-term prognosis for coronary artery disease. Clin Biochem 43:640-644.

Bossé Y, Mathieu P and Pibarot P (2008) Genomics: the next step to elucidate the etiology of calcific aortic valve stenosis. J Am Coll Cardiol 51:1327-1336.

Bouchareb R, Mahmut A, Nsaibia MJ, Boulanger MC, Dahou A, Lépine J, Laflamme M, Hadji F, Couture C, Trahan S et al. (2015) Autotaxin derived from lipoprotein(a) and valve interstitial cells promotes inflammation and mineralization of the aortic valve. Circulation 132:677-690.

Budoff M, Mao S, Takasu J, Shavelle D, Zhao X and OBrien K (2002) Reproducibility of electrom-beam CT measures of aortic valve calcification. Acad Radiol 9:1122-1127.

Cao J, Steffen BT, Budoff M, Post WS, Thanassoulis G, Kestenbaum B, Mcconnell JP, Warnick R, Guan W and Tsai MY (2016) Lipoprotein(a) levels are associated with subclinical calcific aortic valve disease in white and black individuals: The multi-ethnic study of atherosclerosis. Arterioscler Thromb Vasc Biol 36:1003-1009.

Cardoso-Saldaña G, Ize-Lema I, Kimura LY, Zamora González J and Posadas-Romero C (1997) Lipoprotein(a) and cardiovascular risk in adult Mexicans. Rev Invest Clin 49:85-92.
Cardoso-Saldaña G, De La Pena-Diaz A, Zamora-Gonzalez J, Gomez-Ortega R, Posadas-Romero C, Izaguirre-Avila R, Malvido-Miranda E, Morales-Anduaga ME and AnglesCano E (2006) Ethnicity and lipoprotein(a) polymorphism in Native Mexican populations. Ann Hum Biol 33:202-212.

Coté N, Mahmut A, Bosse Y, Couture C, Pagé S, Trahan S, Boulanger MC, Fournier D, Pibarot P and Mathieu P (2013) Inflammation is associated with the remodeling of calcific aortic valve disease. Inflammation 36:573-581.

Danesh J, Collins R and Peto R (2000) Lipoprotein(a) and coronary heart disease. Meta-analysis of prospective studies. Circulation 102:1082-1085.

DeLong D, DeLong E, Wood P, Lippel K and Rifkind BM (1986) A comparison of methods for the estimation of plasma lowand very low-density lipoprotein cholesterol. JAMA 256:2372-2377.

Dumitrescu L, Glenn K, Brown-Gentry K, Shephard C, Wong M, Rieder MJ, Smith JD, Nickerson DA and Crawford DC (2011) Variation in LPA is associated with Lp(a) levels in three populations from the Third National Health and Nutrition Examination Survey. PLoS One 6:e16604.

Edep M, Shirani J, Wolf P and Brown DL (2000) Matrix metalloproteinase expression in nonrheumatic aortic stenosis. Cardiovasc Pathol 9:281-286.

Glader CA, Birgander LS, Söderberg S, Ildgruben HP, Saikku P, Waldenström A and Dahlén GH (2003) Lipoprotein(a), Chlamydia pneumoniae, leptin and tissue plasminogen activator as risk markers for valvular aortic stenosis. Eur Heart J 24:198-208.

Guevara Jr J, Knapp RD, Honda S, Northup SR and Morrisett JD (1992) A structural assessment of the apo(a) protein of human lipoprotein(a). Proteins 12:188-199.

Haffner SM, Gruber KK, Morales PA, Hazuda HP, Valdez RA, Mitchell BD and Stern MP (1992) Lipoprotein(a) concentrations in Mexican Americans and non-Hispanic whites: The San Antonio Heart Study. Am J Epidemiol 136:1060-1068.

Hernández-Avila M, Romieu I, Parra S, Hernández-Avila J, Madrigal H and Willett W (1998) Validity and reproducibility of a food frequency questionnaire to assess dietary intake of women living in Mexico City. Salud Publica Mex 40:133-140.

Kamboh MI, Rewers M, Aston CE and Hamman RF (1997) Plasma apolipoprotein A-I, apolipoprotein B, and lipoprotein(a) concentrations in normoglycemic Hispanics and non-Hispanic whites from the San Luis Valley, Colorado. Am J Epidemiol 146:1011-1018.

Kamstrup PR, Tybjærg-Hansen A and Nordestgaard BG (2014) Elevated lipoprotein(a) and risk of aortic valve stenosis in the general population. J Am Coll Cardiol 63:470-477.

Lahiri DK and Nurnberger JI (1991) A rapid non-enzymatic method for the preparation of HMW DNA from blood for RFLP studies. Nucleic Acids Res 19:5444.

Lanktree MB, Anand SS, Yusuf S and Hegele RA (2010) Comprehensive analysis of genomic variation in the LPA locus and its relationship to plasma lipoprotein(a) in South Asians, Chinese, and European Caucasians. Circ Cardiovasc Genet 3:39-46.

Mahmut A, Boulanger M, El Husseini D, Fournier D, Bouchareb R, Després J, Pibarot P, Bossé Y and Mathieu P (2014) Elevated expression of lipoprotein-associated phospholipase 
A2 in calcific aortic valve disease: implications for valve mineralization. J Am Coll Cardiol 63:460-469.

Marcovina SM, Albers JJ, Scanu AM, Kennedy H, Giaculli F, Berg K, Couderc R, Dati F, Rifai N, Sakurabayashi I et al. (2000) Use of reference material proposed by the International Fedration of Clinical Chemistry and Laboratory Medicine to evaluate analytical methods for the determination of plasma lipoprotein(a). Clin Chem 46:1956-1967.

Mautner GC, Mautner SL, Froehlich J, Feuerstein IM, Proschan MA, Roberts WC and Doppman JL (1994) Coronary artery calcification: Assessment with electrom beam CT and histomorphometric correlation. Radiology 192:619-623.

McLean JW, Tomlinson JE, Kuang WJ, Eaton DL, Chen EY, Fless GM, Scanu AM and Lawn RM (1987) cDNA sequence of human apolipoprotein(a) is homologous to plasminogen. Nature 330:132-137.

Mehrabi MR, Sinzinger H, Ekmekcioglu C, Tamaddon F, Plesch K, Glogar HD, Maurer G, Stefenelli T and Lang IM (2000) Accumulation of oxidized LDL in human semilunar valves correlates with coronary atherosclerosis. Cardiovasc Res 45:874-882.

Messika-Zeitoun D, Aubry MC, Detaint D, Bielak LF, Peyser PA, Sheedy PF, Turner ST, Breen JF, Scott C, Tajik AJ et al. (2004) Evaluation and clinical implications of aortic valve calcification measured by electron-beam computed tomography. Circulation 110:356-362.

Miller J, Weiss R and Heistad DD (2011) Calcific aortic valve stenosis: Methods, models, and mechanisms. Circ Res 108:1392-1412.

Nasir K, Katz R, Al-Mallah M, Takasu J, Shavelle DM, Carr JJ, Kronmal R, Blumenthal RS, O'Brien K and Budoff MJ (2010) Relationship of aortic valve calcification with coronary artery calcium severity: The Multi-Ethnic Study of Atherosclerosis (MESA). J Cardiovasc Comput Tomogr 4:41-46.

Nordestgaard BBG, Chapman MJ, Ray K, Borén J, Andreotti F, Watts GF, Ginsberg H, Amarenco P, Catapano A, Descamps OS et al. (2010) Lipoprotein(a) as a cardiovascular risk factor: Current status. Eur Heart J 31:2844-2853.

Otto C, Lind B, Kitzman D, Gersh B and Siscovick DS (1999) Association of aortic-valve sclerosis with cardiovascular mortality and morbidity in the elderly. $\mathrm{N}$ Engl $\mathrm{J}$ Med 341:142-147.

Rajamannan N, Evans F, Aikawa E, Grande-Allen K, Demer L, Heistad D, Simmons C, Masters K, Mathieu P, O’Brien K et al. (2011) Calcific aortic valve disease: Not simply a degenerative process: A review and agenda for research from the National Heart and Lung and Blood Institute Aortic Stenosis Working Group. Executive summary: Calcific aortic valve disease - 2011 update. Circulation 124:1783-1791.

Santos PC, Bueno CT, Lemos PA, Krieger JE and Pereira AC (2014) LPA rs 10455872 polymorphism is associated with coronary lesions in Brazilian patients submitted to coronary angiography. Lipids Health Dis 13:74.

Silva-Zolezzi I, Hidalgo-Miranda A, Estrada-Gil J, FernandezLopez JC, Uribe-Figueroa L, Contreras A, Balam-Ortiz E, del Bosque-Plata L, Velazquez-Fernandez D, Lara C et al. (2009) Analysis of genomic diversity in Mexican Mestizo populations to develop genomic medicine in Mexico. Proc Natl Acad Sci U S A 106:8611-8616.

Smith JG, Luk K, Schulz CA, Engert JC, Do R, Hindy G, Rukh G, Dufresne L, Almgren P, Owens DS et al. (2014) Cohorts for Heart and Aging Research in Genetic Epidemiology (CHARGE) Extracoronary Calcium Working Group. Association of low-density lipoprotein cholesterol-related genetic variants with aortic valve calcium and incident aortic stenosis. JAMA 312:1764-1771.

Stewart BF, Siscovick D, Lind BK, Gardin JM, Gottdiener JS, Smith VE, Kitzman DW and Otto CM (1997) Clinical factors associated with calcific aortic valve disease. J Am Coll Cardiol 29:630-634.

Taleb A, Witztum J and Tsimikas S (2011) Oxidized phospholipids on apoB-100-containing 1 ipoproteins: A biomarker predicting cardiovascular disease and cardiovascular events. Biomark Med 5:673-694.

Taylor HA Jr, Clark BL, Garrison RJ, Andrew ME, Han H, Fox ER, Arnett DK, Samdarshi T and Jones DW (2005) Relation of aortic valve sclerosis to risk of coronary heart disease in African-Americans. Am J Cardiol 95:401-404.

Thanassoulis G, Campbell CY, Owens DS, Smith JG, Smith AV, Peloso GM, Kerr KF, Pechlivanis S, Budoff MJ and Harris TB (2013) Genetic associations with valvular calcification and aortic stenosis. N Engl J Med 368:503-512.

Villarreal-Molina T, Posadas-Romero C, Romero-Hidalgo S, Antúnez-Argüelles E, Bautista-Grande A, Vargas-Alarcón G, Kimura-Hayama E, Canizales-Quinteros S, Juárez-Rojas JG and Posadas-Sánchez R (2012) The ABCA1 gene R230C variant is associated with decreased risk of premature coronary artery disease: The genetics of atherosclerotic disease (GEA) study. PLoS One 7:e49285.

Vongpromek R, Bos S, Ten Kate G, Yahya R, Verhoeven A, de Feyter P, Kronenberg F, Roeters van Lennep J, Sijbrands E and Mulder MT (2015) Lipoprotein(a) levels are associated with aortic valve calcification in asymptomatic patients with familial hypercholesterolaemia. J Intern Med 278:166-173.

Yutzey K, Demer L, Body S, Huggins G, Towler D, Giachelli C, Hofmann-Bowman MA, Mortlock D, Rogers M, Sadeghi M et al. (2014) Calcific aortic valve disease: A consensus summary from the Alliance of Investigators on Calcific Aortic Valve Disease. Arter Thromb Vasc Biol 34:2387-2393.

\section{Associate Editor: Maria Angélica Cortez}

License information: This is an open-access article distributed under the terms of the Creative Commons Attribution License (type CC-BY), which permits unrestricted use, distribution and reproduction in any medium, provided the original article is properly cited. 